\section{Letramentos a distância na (e na pós) pandemia}

\author{
Distance literacy in (and post) pandemic
}

\section{Petrilson Pinheiro (D) 0}

petrilson@iel.unicamp.br

Universidade Estadual de Campinas - Unicamp

\section{Resumo}

Neste ensaio, discuto a questão dos letramentos no contexto atual de pandemia de Covid-19, a fim de repensar a educação, em particular a educação básica, através de uma reflexão que envolve revisitar o passado, analisar criticamente o presente para, então, imaginar o futuro. Faço um exercício crítico dialético, em que as ideias se desenvolvem a partir de teses, antíteses e sínteses, de uma forma ambivalente, procurando ver tensões, contradições e diálogos comuns, sem endeusar ou demonizar possibilidades. Concluo que é preciso estabelecer diretrizes aos professores que sejam factíveis e flexíveis, sobretudo em relação à infraestrutura tecnológica mínima e às condições de trabalho dos docentes, respeitando a realidade de cada contexto e as propostas pedagógicas de cada escola. Neste momento, é fundamental também que as escolas e os professores considerem a diversidade de estudantes atendidos, buscando verificar que recursos os alunos efetivamente têm para propiciar oportunidades de aprendizagem a todos.

\section{Palavras-chave}

Letramento a distância; Ensino Remoto; Educação Básica; Pandemia.

\section{Abstract}

In this paper, I discuss the issue of literacy in the current context of the Covid-19 pandemic, in order to rethink education, in particular, the basic education, through a reflection that involves revisiting the past, critically analyzing the present and then imagining the future. I do a critical dialectical exercise, in which ideas are developed from theses, antitheses and syntheses, in an ambivalent way, trying to see tensions, contradictions and common dialogues, without deifying or demonizing possibilities. I conclude that it is necessary to establish guidelines for teachers that are feasible and flexible, especially in relation to the minimum technological infrastructure and the working conditions of teachers, respecting the reality of each context and the pedagogical proposals of each school. At this time, it is also essential that schools and teachers consider the diversity of students served, seeking to verify what resources students effectively must provide opportunities of learning for all.

\section{Keywords}

Distance literacy; Remote Teaching; Basic education; Pandemic.

\section{Considerações Iniciais}

Este texto é uma versão de uma palestra que proferi no dia 5 de maio de 2020, transmitida pelo ca-

\section{Linguagęm Foco}

Revista do Programa de Pós-Graduação em Linguística Aplicada da UECE

FLUXO DA SUBMISSÃO

Submissão do trabalho: 02/07/2020

Aprovação do trabalho: 15/07/2020

Publicação do trabalho: 25/09/2020

$0.46230 / 2674-8266-12-3603$

\section{COMO CITAR}

PINHEIRO, Petrilson. Letramento a distância na (e na pós) pandemia. Revista Linguagem em Foco, v.12, n.2, 2020. p. 355 - 369. Disponível em: https://revistas.uece.br/index. php/linguagememfoco/article/ view/3603.

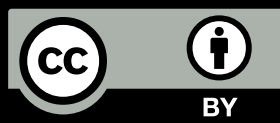


nal do Youtube "Multiletramentos e ensino", que é organizado pelo grupo de pesquisa do CNPQ "Multiletramentos na escola por meio da Hipermídia", coordenado por mim. Destaco também, já de início, que, ao usar no título deste texto o termo "letramento a distância" (LaD), procuro estabelecer um contraponto com o termo "educação a distância" (EaD), assim como busco ir além da discussão atual sobre uso das tecnologias no contexto da pandemia. Com isso, os objetivos deste texto são dois: 1) discutir a questão dos letramentos no contexto atual de pandemia; 2) fazer desse momento tão único e complexo uma possibilidade de repensar a educação, em particular a educação básica, através de uma reflexão que envolve revisitar o passado, analisar criticamente o presente para, então, imaginar o futuro. Ao traçar esses objetivos, procuro fazer um exercício crítico dialético, em que as ideias se desenvolvem a partir de teses, antíteses e sínteses, de uma forma ambivalente, procurando ver tensões, contradições e diálogos comuns, sem endeusar ou demonizar possibilidades.

Para iniciar, então, a discussão que permeia os dois objetivos, gostaria de trazer aqui o conceito de nostalgia, de Svetlana Boym, do seu livro The Future of Nostalgia (O Futuro da Nostalgia), publicado em 2001: "nostalgia é um sentimento de perda e de deslocamento, mas também é um romance da pessoa com sua própria fantasia. A nostalgia inevitavelmente reaparece como um mecanismo de defesa em um tempo de ritmos da vida acelerados e de sublevações históricas" (p. 9). Esse mecanismo de defesa, segundo a autora, é a "promessa de reconstruir o lar ideal que se encontra no núcleo de muitas poderosas ideologias atuais, nos tentando a renunciar ao pensamento crítico em prol do vínculo afetivo. O perigo da nostalgia é que ela tende a confundir o lar verdadeiro com o lar imaginário" (p. 10).

Ao trazer para este texto a noção de nostalgia de Svetlana Boym, quero argumentar que, muitas vezes, temos a ideia imaginária de que, no passado, a vida era melhor - incluindo a educação -, por isso, a sensação de nostalgia. A educação pode até ter sido, em algum momento no passado, melhor do que a atual, mas certamente não era melhor para a maioria. Nesse sentido, ao observarmos os dados mais recentes do Instituto Nacional de Estudos e Pesquisas Educacionais Anísio Teixeira (INEP), relativos à taxa de analfabetismo no Brasil, em 1950, o percentual de analfabetos era de 50,6\%; em 1970, 33,7\%; no ano 2000, 13,6\%; e, em 2018 , de $6,8 \%$. Já o número médio de anos de estudos no Brasil era de 2,4 anos

1 https://www.youtube.com/channel/UCqsntEk6di6LcVIORII71Ew 
em 1970; 5 anos, em 1990; e de 9,3 anos, em $2018^{2}$.

Mesmo para aqueles que estão frequentando a escola atualmente, o ambiente escolar não é muito convidativo: a grande maioria das salas de aula ainda mantém um modelo de organização praticamente inalterado nos últimos duzentos anos, com uma organização das carteiras escolares em fileiras (um aluno atrás do outro), que impede que os alunos possam ver uns aos outros, com o professor ocupando uma posição central à frente dos alunos. Estes, então, devem permanecer em silêncio (às vezes por horas!), enquanto ouvem o professor e copiam em seus cadernos o que o "mestre" escreve na lousa. Por outro lado, há uma quantidade cada vez maior de crianças e adolescentes que lidam, cada vez mais, com tipo de informação multidirecional, multifacetado, multissemiotizado. Nesse sentido, nossos alunos são cada vez mais multitarefas, enquanto a escola, em geral, lida com um modo linear e sequencial de atividades, que, portanto, não dialoga, em geral, com a realidade de muitos de nossos discentes.

Se, por um lado, essa constatação é verdadeira, o que justificaria, de fato, repensar várias questões relacionadas às práticas de letramentos escolares; por outro, é usada por muitos para defender indiscriminadamente a EaD. Diante dessa ambivalência, precisamos ser cautelosos e examinar não apenas as leis, mas, sobretudo, o contexto atual. A esse respeito, destaco, por exemplo, o Decreto 9.057, de 2017, que é particularmente relevante para essa discussão, pois, logo no seu Art. $1^{\circ}$, define a EaD: "para os fins deste Decreto, considera-se educação a distância a modalidade educacional na qual a mediação didático-pedagógica nos processos de ensino e aprendizagem ocorra com a utilização de meios e tecnologias de informação e comunicação, com pessoal qualificado, com políticas de acesso, com acompanhamento e avaliação compatíveis, entre outros, e desenvolva atividades educativas por estudantes e profissionais da educação que estejam em lugares e tempos diversos"3.

Ainda no mesmo decreto, enfatizo o Art. $8^{\circ}$, o qual é taxativo ao determinar que "compete às autoridades dos sistemas de ensino estaduais, municipais e distrital, no âmbito da unidade federativa, autorizar os cursos e o funcionamento de instituições de educação na modalidade a distância nos seguintes níveis e modalidades: I - ensino fundamental, nos termos do $\S 4^{\circ}$ do art. 32 da Lei $n^{\circ} 9.394$, de 20 de dezembro de 1996". Este parágrafo $\left(4^{\circ}\right)$ da Lei 9.394 aponta que o "ensino fundamental será presencial, sendo o ensino a distância utilizado como comple-

2 http://portal.inep.gov.br/documents/186968/485745/Mapa+do+analfabetismo+no+Brasil/a53ac9eec0c0-4727-b216-035c65c45elb?version=1.3

3 http://www.planalto.gov.br/ccivil_03/_ato2015-2018/2017/decreto/d9057.htm 
mentação da aprendizagem ou em situações emergenciais" ${ }^{4}$ (grifos meus).

Parece-me que é justamente o final desse parágrafo $4^{\circ}$ que vem sendo mencionado como pretexto, no momento atual de pandemia, para desenvolver atividades de EaD na educação básica. Todavia, ainda que haja, de fato, amparo legal para fazer isso, precisamos, para além das leis, ter um olhar atento para o contexto complexo atual da pandemia. Nesse contexto, vemos que, no Brasil, o que vem sendo, em geral, adotadas são apenas medidas paliativas para minimizar o impacto da suspensão das aulas presenciais nas instituições de ensino.

Primeiramente, deve-se levar em consideração que a realidade socioeconômica no Brasil ainda é bastante excludente. Segundo a mais recente edição da Pesquisa Nacional por Amostra de Domicílios Contínua - Tecnologia da Informação e Comunicação (Pnad Contínua TIC 2019), divulgada no mês de abril deste ano pelo Instituto Brasileiro de Geografia e Estatística (IBGE) ${ }^{5}$, uma em cada quatro pessoas no Brasil não tem acesso à internet, o que, em números, representa cerca de 46 milhões de brasileiros. É preciso também destacar que muitos alunos, sobretudo os de escola pública, mesmo os que têm acesso à internet, não têm facilidade de acesso a plataformas específicas de ensino a distância, porque não possuem computadores adequados ou porque não têm internet com uma boa velocidade em casa para estudar e pesquisar. Há ainda outros fatores potencialmente complicadores, como, por exemplo, a falta de um espaço adequado para estudar, dificuldades familiares e financeiras, problemas de saúde física e psicológica, etc.

Além disso, muitos professores, para fazer com que as suas aulas não sejam interrompidas nesse período de pandemia, são levados ao esgotamento físico e mental, bem como a situações de controle exagerado por parte das famílias dos alunos e das instituições de ensino em que esses professores trabalham. Essa adaptação paliativa, sem o devido preparo, tem feito com que muitas das atividades usadas pelos professores se tornem ainda mais maçantes e difíceis de serem cumpridas pelos alunos. Exemplos dessas atividades são as aulas frequentes transmitidas em tempo síncrono por meio de ferramentas digitais, que são difíceis de serem acompanhadas pelos alunos, pois muitos deles podem ter dificuldade de acesso à internet; ou ainda o envio frequente, por e-mail ou WhatsApp, de tarefas digitalizadas para os alunos. Muitas vezes estes alunos são ajudados pelos pais, que têm de se desdobrar para fazê-las junto com os filhos no tempo

\footnotetext{
$\overline{4}$ http://www.planalto.gov.br/ccivil_03/leis/19394.htm

5 https://agenciadenoticias.ibge.gov.br/media/com_mediaibge/ arquivos/8ff41004968ad36306430c82eece3173.pdf
} 
determinado pelo professor, em meio a tantas outras atividades de trabalho que precisam também realizar.

É preciso lembrar que os professores, na sua grande maioria, foram preparados para o ensino presencial, porém, no momento atual, estão tendo que se submeter, sem a formação e a estrutura adequadas, a práticas de EaD. De repente, todos nós viramos youtubers. Isso, por um lado, traz problemas de saúde física e mental para os professores, e, por outro, coloca indubitavelmente em xeque a qualidade daquilo que é ensinado, já que, em geral, não houve sequer um treinamento para fazer as adaptações necessárias.

Esses problemas, de fato, existem e são muito relevantes para entendermos, ainda que em linhas gerais, a complexidade do contexto atual e as adaptações feitas para atender a esse contexto. Contudo, devemos também lembrar que, antes da pandemia, a educação no Brasil não se encontrava em "berço esplêndido". Embora tenhamos atingido praticamente a universalização do ensino fundamental, ainda temos muitos problemas de desempenho e desigualdade educacional no Brasil, que estão relacionados à renda, cor ou raça, entre outros fatores. Por exemplo, apenas para ficar na questão da renda, segundo a Síntese de Indicadores Sociais do IBGE $(2019)^{6}$, o abandono escolar é oito vezes maior entre jovens de famílias mais pobres.

Feita essa reflexão sobre o presente, é preciso, então, pensar o futuro. Para tanto, é preciso que haja, antes de tudo, políticas de educação de curto, médio e longo prazo bem definidas. No curto prazo, o Ministério da Educação, em parceria com as secretarias de educação estaduais e municipais, deve preparar e divulgar muito bem como podem ser conduzidas as atividades online. 0 momento da pandemia é extraordinariamente adverso, por isso, não é hora de se prender a regras, mas sim em princípios, como a liberdade de cátedra e a equidade, respeitando às limitações técnicas e de acesso dos professores e alunos, sobretudo dos mais vulneráreis.

Como base, então, em princípios, é preciso estabelecer diretrizes aos professores que sejam factíveis e flexíveis, sobretudo em relação à infraestrutura tecnológica mínima e às condições de trabalho dos docentes, respeitando a realidade de cada contexto e as propostas pedagógicas de cada escola, e apontando também quais serão as providências a serem tomadas quanto à recomposição do calendário letivo escolar.

As secretarias de educação, junto com as diretorias de ensino e as gestões das escolas, devem criar e estimular projetos virtuais voltados à ajuda mútua en$\overline{6}$ https://biblioteca.ibge.gov.br/visualizacao/livros/liv101678.pdf 
tre professores e alunos, criando espaços para troca de experiências de enfrentamento à situação atual de distanciamento. Além disso, poderiam ser oferecidos aos professores, neste momento de pandemia, cursos de formação voltados ao uso de tecnologias digitais, levando em consideração, é claro, suas necessidades e limitações de acesso.

É fundamental também que, neste momento, as escolas e os professores considerem a diversidade de estudantes atendidos, buscando verificar que recursos os alunos efetivamente têm para propiciar oportunidades de aprendizagem a todos. Isso significa que não deve haver aulas neste momento de pandemia? Deve haver aulas sim, mas não aulas formais, típicas do modelo escolar tradicional. É muito importante que o contato por meio de tecnologias digitais seja mantido nesse período de pandemia entre professores e alunos, contato esse que deve valorizar muito mais a troca de experiências do que a aquisição de conteúdo escolar.

Então, se deve haver aulas, o que é importante ensinar e aprender neste momento de pandemia? Indubitavelmente, mais importante do que ensinar o que é uma oração reduzida de infinitivo ou relações métricas no triângulo retângulo, é ensinar valores éticos e respeito à diversidade (em diferentes esferas). Isso poderia inclusive ser feito por meio do trabalho com gêneros jornalísticos e da vida cotidiana, mais comuns aos alunos, explorando, menos questões formais linguísticas e mais as competências de leitura e produção multimodal. Por isso, durante esse período de pandemia, não deve haver cobrança de presença, nem mesmo exigência de atividades diárias por parte dos alunos, pois nenhum estudante deve ser prejudicado por não ter acesso à internet.

De fato, não deveria sequer haver obrigatoriedade de realização das atividades a distância nesse período, uma vez que as realidades educacionais no Brasil são muito diversas. Pensemos, por exemplo, como seriam as aulas a distância para muitas comunidades indígenas, quilombolas e de assentados, em que o acesso a recursos tecnológicos são ainda mais difíceis. Por isso, é preciso levar em conta, mormente, as necessidades específicas dessas comunidades, em que a realização das tarefas tradicionais, por exemplo, poderia ser considerada, neste momento, como atividades educacionais, que poderiam ser registradas e mostradas aos professores quando as escolas então voltassem à normalidade com as aulas presenciais.

No médio e longo prazos, por sua vez, é preciso criar mecanismos que atuem para melhorar a qualidade da educação, o que depende dos poderes legislativo e executivo. Por exemplo, já tramita há bastante tempo no Congresso 
Nacional uma proposta de destinar 10\% do PIB para a educação. Atualmente, o Brasil investe apenas um pouco mais da metade desse percentual. Ainda no que diz respeito ao investimento em educação, outro dado é bastante relevante: o Brasil investe bem menos por aluno do que a média dos países da Organização para a Cooperação e Desenvolvimento Econômico_(OCDE) ${ }^{7}$. Enquanto no Brasil o valor por aluno no ensino fundamental II é de \$3.700,00 por ano, a média da OCDE é de \$10.200 (quase 3 vezes mais!).

Contudo, não basta apenas aumentar o investimento em educação. Em que é preciso investir? Primeiramente, deve haver investimento tecnológico. Por exemplo, há projetos de investimento em tecnologia nas escolas públicas paralisados, tanto na compra de equipamentos quanto de internet com melhor velocidade para uso de alunos e professores. Dados do Censo da Educação Básica de $2019^{8}$ mostram que, apesar de serem a grande maioria, as escolas do ensino fundamental das redes municipais são as que menos dispõem de bibliotecas ou salas de leitura (41\%) e de recursos tecnológicos, como lousa digital (8,8\%), computador de mesa (34,3\%) ou portátil $(20,4 \%)$ e internet disponível para uso dos alunos (21,1\%). Além do acesso à internet na escola, deveria haver um grande projeto de investimento em internet e computadores para que os alunos possam também ter acesso em casa, justamente para tentar diminuir as desigualdades de acesso entre os alunos fora do contexto escolar.

Além do investimento em tecnologia, é necessário que haja, sobretudo, investimento humano. Nesse ponto, é fundamental o investimento na formação docente, tanto a inicial, por meio dos cursos de licenciatura; quanto a continuada, por meio de cursos de extensão e pós-graduação, buscando, inclusive, promover incentivos para a carreira profissional docente, com a criação de planos de carreira bem estruturados. A esse respeito, vale destacar que o Censo da Educação Básica de $2019^{9}$ mostra que, nos anos finais do ensino fundamental, o indicador de adequação da formação docente apresenta uma variação de 37\% (artes) a 67\% (língua portuguesa), ou seja, cerca de metade dos professores que atuam no ensino fundamental não são formados nas disciplinas em que atuam. O censo também mostra que apenas $41 \%$ dos docentes têm alguma pós-graduação e 38\% algum tipo de formação continuada até 2019.

Esses dados relativos à formação docente têm indubitavelmente impacto

\footnotetext{
7 https://www.oecd.org/brazil/Education-at-a-glance-2015-Brazil-in-Portuguese.pdf

8 http://portal.inep.gov.br/documents/186968/O/Notas+Estat\%C3\%ADsticas+-+Censo+da+Educa\%C3\% A7\%C3\%A3o+B\%C3\%A1sica+2019/43bf4c5b-b478-4c5d-ae17-7d55ced4c37d?version=1.0

9 http://portal.inep.gov.br/documents/186968/O/Notas+Estat\%C3\%ADsticas+-+Censo+da+Educa\%C3\% A7\%C3\%A3o+B\%C3\%A1sica+2019/43bf4c5b-b478-4c5d-ae17-7d55ced4c37d?version=1.0
} 
na sua atuação em sala de aula. Isso porque, apesar de muitos professores procurarem fazer um trabalho comprometido e sério, muitos docentes trabalham com materiais didáticos de forma inflexível, o que dificulta qualquer tipo de inovação e restringe as oportunidades de realizar um trabalho colaborativo e de valorização dos saberes, culturas e histórias dos discentes, que, antes de aprender por meio de teorias, conectam-se e aprendem muito mais a partir do que vivenciam, a partir do que experimentam.

Essa percepção sobre o processo de ensino e aprendizagem é fundamental porque o simples uso de novas tecnologias no ensino não resolve, pois isso pode simplesmente replicar práticas tradicionais de ensino, como ainda acontece bastante em muitas escolas e o que está acontecendo no contexto atual de pandemia, com vídeo-aulas e testes on-line, que, de uma certa forma, replicam práticas de letramentos tradicionais de sala de aula. A esse respeito, os autores Michelle Knobel e o Colin Lankshear, em seu livro A New Literacies Sampler (Uma Amostra dos Novos Letramentos), publicado em 2007, apontam que, o mais importante não é usar as novas tecnologias, mas sim que as "novas tecnologias mobilizam tipos de valores, prioridades, sensibilidades e procedimentos muito diferentes dos letramentos com os quais estamos familiarizados" (KNOBEL e LANKSHEAR, 2007, p. 7).

Vale destacar que a Base Nacional Comum Curricular (BNCC, 2019) compartilha dessa concepção, ao apresentar sete Competências Gerais da Educação Básica, em especial a competência de $n^{\circ} 5$, que mostra justamente como as novas tecnologias podem ser pensadas para trazer novos valores e concepções para a educação: "compreender, utilizar e criar tecnologias digitais de informação e comunicação de forma crítica, significativa, reflexiva e ética nas diversas práticas sociais (incluindo as escolares) para se comunicar, acessar e disseminar informações, produzir conhecimentos, resolver problemas e exercer protagonismo e autoria na vida pessoal e coletiva" (BNCC, 2019, p. 9) ${ }^{10}$.

Essa competência da BNCC dialoga muito fortemente com a ideia de "letramentos" com a qual venho trabalhando e pesquisando há alguns anos, que, conforme uso no título deste texto ("letramentos a distância"), é algo bem mais amplo do que EaD. Essa concepção mais abrangente de letramentos busca reconhecer a multiplicidade de práticas de letramentos, tanto aquelas valorizadas na escola, típicas de práticas de letramentos grafocêntricas, passando por aquelas

$\overline{10 \quad h t t p: / / b a s e n a c i o n a l c o m u m . m e c . g o v . b r / i m p l e m e n t a c a o / p r a t i c a s / c a d e r n o-d e-p r a t i c a s / ~}$ aprofundamentos/193-tecnologias-digitais-da-informacao-e-comunicacao-no-contexto-escolarpossibilidades 
não valorizadas no contexto escolar, que envolvem diferentes culturas não hegemônicas, àquelas mediadas por tecnologias digitais de comunicação e informação, não se limitando, assim, somente a estas, como as da EaD.

Essa perspectiva de letramentos reconhece, portanto, a importância dos diferentes espaços sociais de aprendizagem para a formação do alunado. Nesse sentido, a escola não é apenas um espaço físico, um prédio onde os alunos devem estudar, mas se constitui em um espaço social, composto de pessoas e suas relações. Por isso, as aulas presenciais na escola são primordiais para o processo de aprendizagem, tanto para desenvolvimento socioemocional dos alunos, nas relações com colegas e professores, importantes para que os estudantes aprendam a conviver com as diferenças, quanto para o seu desenvolvimento cognitivo, aprendendo de forma mais próxima com os professores e com os próprios colegas.

Refletir sobre essas questões me leva, então, a fazer a seguinte pergunta: o que é ser letrado hoje? Essa questão se remete ao "letramento crítico", um conceito que desempenha um papel fundamental no processo de emancipação e formação de professores e estudantes críticos. Alguns autores (GEE, 1996; CERVETTI; PARDALES; DAMICO, 2001; LUKE, 2004) propõem uma visão de letramento crítico fortemente influenciada pela teoria crítica social de Paulo Freire (1982), cujo objetivo é considerar os letramentos como práticas sociodiscursivas que permitem uma compreensão crítica e um questionamento de forças e construtos ideológicos, de modo a empoderar e transformar indivíduos. Dentro dessa perspectiva, o conceito de letramento crítico, conforme aponta Pinheiro (2018), é baseado na ideia de que as representações são sempre ideológicas, que influenciam e constituem as práticas sociais, e que os sujeitos nelas envolvidos devem estar conscientes de tais representações, de modo a aprender a se posicionarem criticamente sobre elas (CERVETTI; PARDALES; DAMICO, 2001). Nesse sentido, ser letrado significa ser crítico. Isso abre a possibilidade de "estar não apenas no mundo, mas com o mundo", em que "o indivíduo não é um espectador", mas um "recriador" (FREIRE, 1982, p. 53).

Ao pensar o letramento crítico no contexto atual, podemos dizer que as pessoas, de uma forma geral, estão cada vez mais conectadas às tecnologias digitais. O celular, mais do que uma "ferramenta tecnológica" que nos ajuda a fazer coisas, já se tornou uma parte importante da nossa cognição, sobretudo para os mais jovens, como os nossos alunos. Contudo, em geral, falta a esses jovens desenvolver o olhar crítico sobre o uso que fazem da internet. Isso quer dizer que, 
muito mais do que buscar informação no mundo virtual, é necessário educar nossos alunos para uma análise crítica das informações com as quais lidam ou podem vir a lidar. Então, entendo que "ser letrado crítico" está, mais do nunca, relacionado ao fato de que a internet pode ser útil tanto para divulgar informações relevantes, quanto informações falsas. Por isso, um letrado crítico não apenas busca informações na rede, mas está, sobretudo, preocupado em avaliar as fontes de informações disponibilizadas na internet.

Um exemplo particularmente é o da Wikipédia. Diferentemente das enciclopédias tradicionais, na Wikipédia, as informações são fluidas, justamente porque o usuário enciclopédia online não é apenas consumidor, mas também produtor de conteúdo. Isso acaba gerando desconfiança nas pessoas e leva muitos, em particular, professores, a não quererem usá-la em suas aulas. A desconfiança em relação à Wikipédia é pertinente, mas e se, em vez de simplesmente descartar seu conteúdo, passássemos a desenvolver com nossos alunos um trabalho de pesquisa sobre as informações que buscamos na internet, que envolve a compreensão e a avaliação crítica das fontes pesquisadas? Isso é mais do que usar a internet para buscar informação: é transformar a pesquisa na internet em objeto de ensino, o que nos leva a ir além do consumo sem reflexão ou da rejeição de conteúdos que encontramos na internet por desconfiança de sua fidedignidade, buscando, assim, discutir e analisar os conteúdos de forma crítica.

Quando proponho transformar a pesquisa na internet em objeto de ensino, quero dizer que é preciso criar parâmetros didático-pedagógicos para fazer isso. Por exemplo, no curso de extensão que venho coordenando desde 2013 no Instituto de Estudos da Linguagem da Unicamp, voltado para a formação continuada de professores da educação básica, temos trabalhado certos parâmetros justamente para trabalhar a pesquisa na internet. No curso de extensão, procuramos discutir os processos de busca de informação que circula na internet; escolher os termos apropriados; entender os resultados de busca; filtrar a busca para obter os melhores resultados; avaliar criticamente as fontes encontradas; e refletir sobre a questão do plágio.

Além do trabalho de pesquisa na internet como objeto de ensino, também propomos nesse curso de extensão atividades que envolvem o que chamo de "leitura multimodal crítica", que é fortemente influenciada pela perspectiva crítica freireana, buscando, assim, discutir (e desconstruir) o caráter político-ideológico de práticas multimodais e digitais atuais. Para exemplificar isso, gostaria de trazer aqui um caso muito recente: uma postagem no Twitter, relacionada ao uso da linguagem, que me pareceu bastante interessante para trabalhar a 
leitura multimodal crítica no contexto de sala de aula por meio de práticas de letramentos no contexto digital. A postagem ocorreu no dia 5 de abril de 2020, em que o então ministro da Educação, Abraham Weintraub, usou o personagem Cebolinha, da revista em quadrinhos Turma da Mônica, para ridicularizar a China, país onde se iniciou a pandemia de COVID-19. No Twitter, Weintraub publicou um post no qual continha uma imagem de uma das capas da revista Turma da Mônica, em que personagens da revista estão na famosa Muralha da China e um deles segura a bandeira chinesa (ver figura a seguir), seguida da mensagem:

\footnotetext{
"Geopolíticamente, quem podeLá saiL foLtalecido, em teLmos Lelativos, dessa cLise mundial? PodeLia seL o Cebolinha? Quem são os aliados no BLasil do plano infalível do Cebolinha paLa dominaL o mundo? SeLia o Cascão ou há mais amiguinhos?"
}

Na mensagem, o ex-ministro troca a letra "r" pela letra "L", buscando chamar a atenção, na escrita, para o modo como fala o personagem Cebolinha - assim como o fazem muitos chineses quando falam português -, o que se caracteriza como lambdacismo, um tipo de dislalia que se constitui na dificuldade ou mesmo na incapacidade de articular o som vibrante [r], substituindo-o pelo som lateral [I]. De fato, ao postar a mensagem, Weintraub não apenas intenta ridicularizar o modo de falar dos chineses, configurando-se como uma espécie de preconceito linguístico de caráter xenófobo e racista, mas também busca insinuar que a China estaria se beneficiando com a crise mundial causada pela pandemia de COVID-19. Isso mostra o quanto a postagem multimodal do ex-ministro da educação (texto escrito e imagem), em um contexto digital específico (o Twitter), está vinculada à sua produção e circulação com o contexto mais amplo (a relação política atual entre Brasil e China).

Com efeito, exemplos atuais como esse do Twitter nos possibilitam analisar criticamente tanto os recursos linguísticos e multissemióticos mobilizados, como aquilo que está regendo e buscando normatizar e estabilizar discursos e identidades, a partir desses arranjos que compõem essas práticas de letramentos. Nesse sentido, essa perspectiva crítica de análise multimodal não apenas nos ajuda a compreender uma determinada realidade sociocultural e histórica, mas também, e sobretudo, nos impulsiona a pensar em possibilidades de ruptura frente a discursos hegemônicos, preconceituosos e opressores, o que potencializa seu caráter transformador.

Figura 1 - Postagem em Rede Social Twitter 


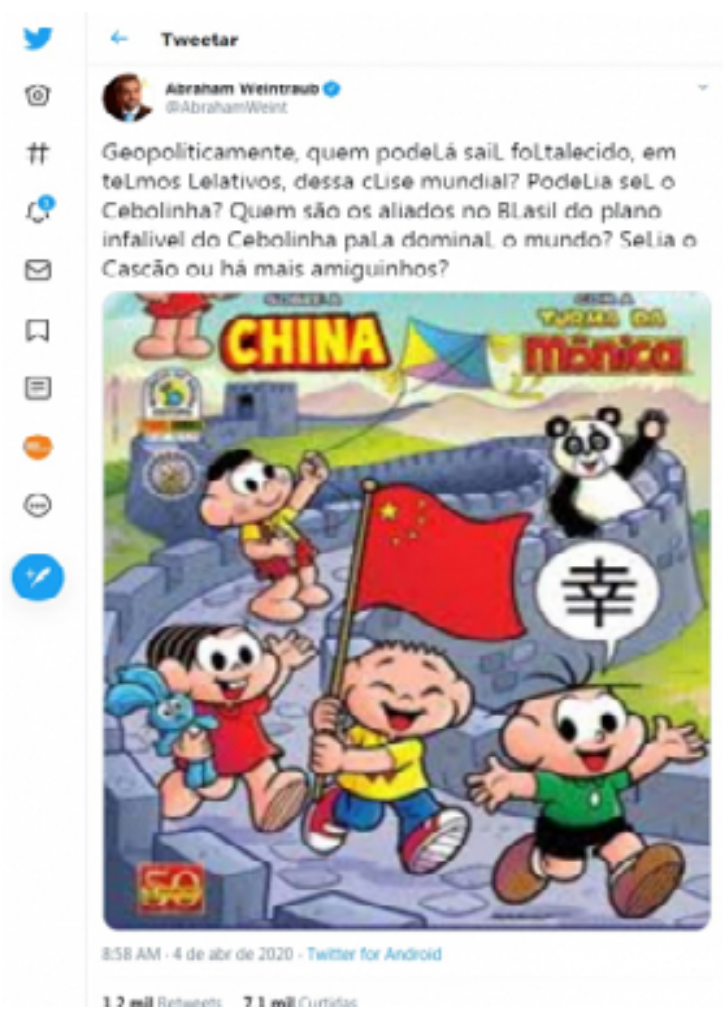

Fonte: https://noticias.uol.com.br/politica/ultimas-noticias/2020/04/06/eu-nao-sou-racista-diz-weintraub-apos-usar-cebolinha-para-ironizar-china.htm?aff_source=56d95533a8284936a374e3a6da3d7996

Contudo, para que um trabalho que envolve tecnologias digitais se torne mais interessante e efetivo, é necessário que se desenvolvam também pedagogias de inteligência colaborativa, em que os alunos ajudam uns aos outros e produzem conteúdo. Por exemplo, devemos envolver nossos alunos em atividades colaborativas de leitura, de escrita e multimodais, por meio do uso de tecnologias digitais, como clubes de leitura a distância, contação de histórias com leitura dramática coletiva (teatro), que pode ser gravada em vídeo, editada e disponibilizada publicamente; gravação em vídeo de uma resenha de uma obra; conversão de um livro em podcast ou vídeo de animação; atividades de escrita colaborativa em plataformas de aprendizagem e até blogs de notícias, com a possibilidade de fazer isso também por meio da produção colaborativa de vídeos.

Tudo isso, é claro, afeta diretamente o processo de avaliação dos alunos. Nesse sentido, a avaliação tradicional testa a memorização de conteúdos que muitas vezes são esquecidos pelos discentes depois de um teste formal. Contudo, se os dispositivos tecnológicos, principalmente os celulares, se tornaram uma espécie de próteses cognitivas de nossos corpos, passamos a lidar com muito mais informação do que jamais poderíamos memorizar para uma simples avaliação. Por isso, mais do que fazermos nossos alunos decorarem conteúdo, preci- 
samos elaborar avaliações que possam, de fato, avaliar a capacidade de busca e seleção de informação e, sobretudo, o pensamento crítico e criativo em relação a essa informação, por meio de um trabalho que não envolve apenas mentes individuais, mas também contribuições colaborativas dos alunos.

Assim, é importante utilizar diferentes instrumentos de avaliação no processo de aprendizagem dos alunos, que envolvem a) elaboração de questões discursivas de caráter reflexivo, com possibilidade de consulta a diferentes fontes, incluído a internet; b) participação e engajamento dos alunos nas aulas; c) atividades online, individuais e colaborativas, sobre as quais os alunos possam não apenas refletir com mais tempo e mais oportunidades de consultar outras fontes de conhecimento, mas também a possibilidade de trocar experiências com outros colegas em um espaço online comum (nessas atividades online, os alunos fazem coisas diferentes em tempos diferentes, individualmente e em grupos, respeitando suas possibilidades de acesso e de produção); d) atividades de produção textual colaborativa, envolvendo inclusive elementos multimodais (texto escrito, vídeos, podcasts, gráficos, etc.); e) atividades de revisão textual, em que cada aluno tem a possibilidade de revisar os trabalhos dos colegas, baseando-se em critérios previamente discutidos entre professor e alunos, o que também envolve a "metacognição", isto é, pensar sobre as suas e as ideias (pensamentos) dos outros; f) atividades de reescrita, que seriam realizadas com base na colaboração dos colegas em versões anteriores; g) atividades de autoavaliação, em que cada aluno tem a possibilidade de se autoavaliar, com base na sua participação em diferentes atividades ao longo da disciplina.

Essas possibilidades variadas de avaliação são mais pertinentes justamente porque partem da concepção de que a aprendizagem não ocorre apenas em sala de aula, nem apenas por meio de recursos de EaD. A própria LEI N 9.394, de 1996, a esse respeito, é bem clara logo no seu Art. 10: "a educação abrange os processos formativos que se desenvolvem na vida familiar, na convivência humana, no trabalho, nas instituições de ensino e pesquisa, nos movimentos sociais e organizações da sociedade civil e nas manifestações culturais"11.

Portanto, a aprendizagem é ubíqua, isto é, ocorre em qualquer tempo e lugar, em um processo que dura a vida toda. Estamos sempre aprendendo. E o mais interessante disso é que, nesse processo de aprendizagem, aprendemos muito com nossos alunos. Por isso, é preciso construir espaços de conhecimento e de experiência colaborativos. Diante disso, levanto, então, a pergunta que não

11 http://www.planalto.gov.br/ccivil_03/leis/19394.htm 
quer calar: quando os professores e os alunos voltarem às aulas, tudo será como antes?

No início deste texto, citei o conceito de nostalgia proposto por Svetlana Boym em seu livro The Future of Nostalgia (O Futuro da Nostalgia), publicado em 2001. Além da definição do conceito, a autora também faz uma diferença importante entre dois tipos de nostalgia: a restauradora e a reflexiva. Para ela, a nostalgia restauradora busca reconstruir algo que foi perdido, por isso, busca a "verdade absoluta" em algo do passado para tentar remontá-lo. A nostalgia reflexiva, por outro lado, "reside nas ambivalências do desejo e do pertencimento humano e não se esquiva das contradições, pois não busca proteger algo, mas justamente colocar isso em dúvida. Portanto, a nostalgia reflexiva "não segue uma única trama, mas explora maneiras de habitar muitos lugares ao mesmo tempo[...]. Na melhor das hipóteses, a nostalgia reflexiva pode apresentar um desafio ético e criativo, não apenas um pretexto para melancolias" (BOYM, 2001, p. 12).

Essa distinção que Svetlana Boym propõe é, a meu ver, interessante para refletirmos sobre a possibilidade de seguirmos não pela nostalgia restauradora, melancólica, mas de uma forma que tente transformar este momento, tão terrível em vários aspectos, em algo que nos faça buscar a nostalgia reflexiva, aprendendo com o passado, trabalhando o presente, para, então, imaginar futuros meIhores. Podemos estar no início de um processo histórico de mudanças em vários âmbitos em nossa sociedade, incluindo a educação. Por isso, precisamos sim sonhar, mas também precisamos ousar, conscientes da importância da educação para o futuro do nosso país e do papel de cada um de nós diante desse desafio ético e criativo para a construção desse futuro.

Ao pensar nessa relação entre passado, presente e futuro, não posso deixar de finalizar este texto com o nosso grande educador, patrono da educação brasileira, Paulo Freire, que, no seu livro Pedagogia da Esperança, publicado em 1992, que é um reencontro com a Pedagogia do Oprimido, afirma de forma cabal: "não há utopia verdadeira fora da tensão entre a denúncia de um presente tornando-se cada vez mais intolerável e o anúncio de um futuro a ser criado, construído, política, estética e eticamente, por pós, mulheres e homens. A nova experiência de sonho se instaura, na medida mesma em que a história não se imobiliza, não morre. Pelo contrário, continua" (FREIRE, 1992, p. 91).

\section{Referências}

BOYM, Svetlana. The Future of Nostalgia. New York: Basic Books, 2001. 
CERVETTI, Gina, PARDALES, Michael J.; DAMICO, James S. A tale of differences: comparing the traditions, perspectives and educational goals of critical reading and critical literacy. Reading Online, v. 4, n. 9, Apr. 2001.

FREIRE, Paulo Reglus Neves. Education as the practice of freedom. Tradução de M. B. Ramos. In: Education for critical consciousness. New York: The Continuum Publishing, 1982. p. 1-84.

Pedagogia da Esperança. Rio de Janeiro: Paz e Terra, 1992.

GEE, James Paul. Social linguistics and literacies: ideology in discourses. 2. ed. London: Taylor \& Francis, 1996.

KNOBEL, Michelle; LANKSHEAR, Collin. A new literacies sampler. New York: Peter Lang, 2007.

LUKE, Allan. Foreword [Prefácio]. In: McLAUGHLIN, Maureen; DEVOOGD, Glenn. Critical literacy: enhancing students' comprehension of text. New York: Scholastic, 2004.

PINHEIRO, Petrilson. Pesquisa em contextos de ensino e aprendizagem por meio do uso da internet: uma ecologia de saberes, Educação e Pesquisa (Online),Vol. 44, pp. 69$84,2018$.

\section{Sobre os autores}

Petrilson Pinheiro - Doutor em Linguística Aplicada pela Universidade Estadual de Campinas (Unicamp) com pós-doutorado na University of Illinois, em Urbana-Champaign, Estados Unidos. Professor e diretor associado do Instituto de Estudos da Linguagem da Unicamp. E-mail: petrilson@iel.unicamp.br. 